\title{
The Study of the Possibility of Using Low-Calorie Foods in the Technology of Flour Confectionery Production
}

\author{
Aleksandr Kaluzhskikh ${ }^{1,}$, Natalya Dolgopolova ${ }^{2}$, Marina Kotelnikova $^{2}$, and Snezhana Ryumshina ${ }^{3}$ \\ ${ }^{1}$ Southwest State University, 94, 50 Let Oktyabrya ul., Kursk, Russia, 305040 \\ ${ }^{2}$ Kursk State Agricultural Academy, 70, Karl Marx ul., Kursk, Russia, 305021 \\ ${ }^{3}$ Kursk Institute of Cooperation (affiliated branch of Belgorod University of Cooperation, Economics \& Law), 116, Radishchev ul., \\ Kursk, Russia, 305004
}

\begin{abstract}
The article demonstrates the advisability of substituting high-grade wheat flour in the formulation of a sponge cake semi-finished mix with the mix of oat, corn and gram flour. An oat, corn and gram flour mix contains much more protein than wheat flour. This mix contains a significant amount of globulin, which suggests an evident foaming capacity of protein systems and is a positive factor in the technology of making sponge cakes. When substituting wheat flour with the suggested mix completely, the nutritional value of finished products improves. The share of dietary fiber increases significantly; the calorie content of products decreases. Absence of gluten makes this mix a strategically important raw material for gluten-free products. It is recommended to use this recipe, since with a complete substitution of wheat flour, there is an improvement in organoleptic, physicochemical indicators of the quality of sponge cake batter and finished products. The use of oat, corn and gram flour leads to an extension of the shelf life of sponge cake semi-finished products and helps to reduce the energy value and increase the vitamin and mineral ones of finished products. The introduction of the mix of flour into the sponge cake batter recipe does not worsen the quality of sponge cakes during storage. The developed formulation can be adapted to the technological process and equipment installed at existing confectionery enterprises and does not require additional costs.
\end{abstract}

The studies of the composition of new types of food products, including those enriched with physiologically functional ingredients, are important and promising, since they make it possible to organize people's nutrition on a scientific and hygienic basis [1].

One of the important trends for improving the technology of bakery and flour confectionery products is to reduce their calorie content, provided that their biological value is maintained or increased. In many countries, recent researches have proposed using various compounds, including dietary fiber and biologically active substances, to create such foods [2].

Reducing the calorie content of bakery and flour confectionery products can be achieved by substituting energy-intensive nutrients or adding:

a) Indigestible food substances processed by physicochemical methods (glucose sorbitol, pectin substances, lignin, microcrystalline cellulose, methylcellulose and its analogs, polyhydric alcohol polycondensation products, etc.);

b) Natural components of plant and animal origin, in particular, vegetables, fruits, bran, crushed grain, dry and concentrated dairy products, flour made from defatted cotton, sunflower, sesame seeds, soybeans, peanuts, sweet potatoes, brewer's grains, etc.

The expansion of the range of confectionery assortment is being carried out by creating new types of low calorie foods with increased nutritional value and is oriented at all categories of consumers.
In modern conditions, the topical problem of the population's health status is lack of vitamins, dietary fiber, macro- and microelements, minerals and essential amino acids or their amount is insufficient in population diets [3].

At the present stage of development of the food industry, confectionery branch is one of the leading ones. The introduction of modern equipment into the production process and an innovative approach to raw materials contributes to the expansion of the range of products produced as well as an increase in demand for finished products.

For the preparation of confectionery, various staple and supplement products are used, which, depending on their type, structure, and purpose, are subjected to preliminary preparation and processing.

The studies by other authors were aimed at developing formulations for a wide range of products, such as bakery products, sausages and soft drinks, using promising types of wild-growing medicinal raw materials, one of the components of which is willow herb [4].

As studies in the area of dietetics show, substitution of a part of unbalanced food products with full-value ones based on plant raw materials, including the use of functional ingredients in the production of confectioneries contributes to an increase in human life expectancy [5].

In connection with the formation of a healthy nutrition system in recent years, it is necessary to develop a technology for the production of confectioneries

${ }^{*}$ Corresponding author: alex-kaluzhskih@yandex.ru 
introducing functional ingredients into their composition; these ingredients do not change the organoleptic properties of the product, but contribute to a decrease in calorie content [6].

The nutritional value and quality of flour confectionery products largely depend on the properties and composition of the prevailing ingredients [7].

One of the promising ways to increase the biological value of shortenings is to expand the range through the use of non-traditional types of ingredients [8].

Premium wheat flour contains gluten; this protein can lead to severe gastrointestinal diseases.

One of the groups of specialized foods includes products that do not contain gluten (a protein of cereals), which causes celiac disease which is a kind of a chronic disease [9, 10].

The reason for these is high calorie content, high glycemic index, and starch.

Oat flour is the simplest and most affordable substitute. It is healthy flour rich in fiber, slow carbohydrates and micronutrients. Oat flour, like oat grain, is low in starch and high in plant fiber and fat. Oat flour contains essential amino acids as well as vitamins A, B, E, choline, enzymes, tyrosine, copper, essential oil, sugar and minerals, including silicon, which plays a special role in metabolism, mineral salts such as calcium, phosphoric ones and dietary fiber.

Corn flour is a very valuable product that is important for humans for its beneficial healing properties. The yellowish powder contains a lot of vitamins, salts and minerals. A rich list of nutrients is represented by dietary fiber (natural fiber), $\mathrm{B}$ vitamins, vitamin $\mathrm{E}$, niacin, potassium, iron, calcium, carotene, magnesium, starch, etc. that make up not a small part of the periodic table. Due to its composition and properties, corn flour is considered extremely useful and better than other varieties, including wheat and rye ones.

Scientists have come to the conclusion that corn flour improves the functioning of the cardiovascular system, normalizes the work of blood circulation, strengthens the walls of blood vessels, and increases their elasticity. Thanks to corn flour, the aging process slows down. The microelements contained in it contribute to strengthening human bones and teeth. Corn bread is very useful for those diagnosed with tuberculosis.

Gram flour is a source of magnesium, phosphorus and iron; it contains a large amount of fiber, complex carbohydrates and amino acids. But the beneficial properties of gram flour are not limited to this. Turkish peas saturate our body with pyrodixin (vitamin $\mathrm{B}_{6}$ ), without which the immune system cannot function. If you do not want to suffer from depression or depend on hormonal fluxes, add gram flour to your diet, which is also useful for people who follow a healthy diet. One can enjoy ordinary meals and lose weight since gram flour is low in glycemic index and calories, gluten free and rich in fiber compared to wheat flour. Despite the undoubted benefits of gram flour, it can be harmful if consumed excessively in cases of cholecystitis, thrombophlebitis, gout, nephritis and inflammatory diseases of the gastrointestinal tract.

Sugar is one of the most common additives used in almost all products: sponge cakes, frosting, hard sauces, ice cream. However, many studies substantiating the dangers of granulated sugar have been carried out recently [11].

An excessive love of sugar can trigger diabetes. The right decision for every person is to exclude this component from his/her diet. Sugar can be substituted with FitParad No. 10 sweetener which, according to the manufacturer, is made exclusively from natural ingredients.

The development of the low-calorie confection was based on the concept of using only natural ingredients.

At the first stage of the study, sponge cake batter was prepared in accordance with the classic recipe presented in table 1 , then partial and complete substitution of wheat flour with oat flour was carried out. The ratio of the components is shown in table 2.

Table 1. Classic recipe for sponge cake semi-finished product

\begin{tabular}{|c|c|c|c|}
\hline \multirow{2}{*}{ Ingredients } & \multirow{2}{*}{$\begin{array}{c}\text { Dry solids weight ratio, } \\
\%\end{array}$} & \multicolumn{2}{|c|}{$\begin{array}{c}\text { Consumption of raw materials per } 100 \mathrm{~g} \text { of } \\
\text { sponge cake }\end{array}$} \\
\cline { 3 - 4 } & & Actual & 19.65 \\
\hline Straight white wheat flour & 85.5 & 35.47 & 18.07 \\
\hline Sanding sugar & 99.85 & 22.3 & 7.01 \\
\hline Melange & 58 & 21.72 & 44.73 \\
\hline Totally & - & 79.49 & 42.00 \\
\hline Yield & 84 & 50.0 & matter \\
\hline
\end{tabular}

Table 2. Recipe for sponge cake semi-finished product with the substitution of wheat flour with oat flour

\begin{tabular}{|c|c|c|c|}
\hline Ingredients & Sample No. 1 (15\%) & Sample No. 2 (35\%) & Sample No. 3 (100\%) \\
\hline Straight white wheat flour & 14.60 & 10.73 & - \\
\hline Oat flour & 4.87 & 6.73 & 22.3 \\
\hline Sanding sugar & 22.3 & 22.3 & 21.72 \\
\hline Melange & 21.72 & 21.72 & 79.49 \\
\hline Totally & 79.49 & 79.49 & 50.0 \\
\hline Yield & 50.0 & 50.0 & \\
\hline
\end{tabular}


Oat flour makes baked goods crumblier and can be used as a substitute for wheat flour. When comparing three samples, Sample No. 2 had the best characteristics. This sample had a porous structure, moderately crumbly with a pleasant flavour. Sample No. 1 was almost identical to the control sample. Sample No. 3 was too fragile and crumbly with a specific oat flour flavour.

When working out the details of the formulas, it was determined that the content of oat flour should not exceed one third of the total amount of wheat flour due to its low gluten content. If the amount of oat flour increases then corn flour should be added to the batter, which will act as a binding component, and will also increase the biological value of baked goods. For baking, mix corn flour with wheat flour in a 1:1 ratio.

Based on the data obtained, instead of wheat flour the following ingredient ratios were used: $35 \%$ of oat flour and $65 \%$ of corn flour.

As can be seen from the data obtained, with a complete substitution of wheat flour with a mix of corn and oat flour, the nutritional value of finished products improves; the share of dietary fiber increases significantly; the calorie content of products decreases.

By combining 3 types of flour (corn flour, oat flour and gram flour), a low-calorie sponge cake recipe presented in table 3 was developed.

Table 3. Low-calorie sponge cake recipe

\begin{tabular}{|c|c|}
\hline Ingredients & Amount, $\mathrm{kg}$ \\
\hline Corn flour & 7 \\
\hline Gram flour & 5 \\
\hline Oat flour & 3 \\
\hline Sparkling mineral water & 10 \\
\hline Sugar substitute & 0,5 \\
\hline Vegetable oil & 5 \\
\hline Vanillin & 0.25 \\
\hline Baking powder & 0.5 \\
\hline Totally & 31.25 \\
\hline
\end{tabular}

The technology for preparing the developed biscuit differs from the classical process.

The cooking process begins with the preparation and weighing of all ingredients; use only room temperature ingredients.

When conducting experimental studies, we used standard techniques accepted in the food industry. When baking sample laboratory sponge cake semi-finished products, the generally accepted and special methods for evaluating the quality of ingredients, semi-finished products and finished products in the confectionery industry were used; these methods are described in the regulatory and technical documentation:

- GOST 5897-90 for determining the organoleptic indicators of product quality [7].

Organoleptic evaluation of semi-finished products was carried out with the participation of 5 tasters. The evaluation was carried out by descriptive scored methods.

In order to evaluate the appearance, the tasters studied the colour of the finished product, its intensity and uniformity, examined the preservation of the shape of the product, the features of the state of the surface of the baked sponge cake, and evaluated the appearance of the fracture of the product.

To determine the quality of the texture of the baked semi-finished product, the tasters touched the product with a table spoon, pressing with different force.

The evaluation of the flavour of the finished product was carried out as follows: the taster held his/her breath for 2-3 seconds and then smelled the product. Through this, the typicality of the biscuit product flavour was evaluated and the presence of foreign flavours was determined.

The evaluation of the taste of the baked semi-finished products was carried out by means of thorough chewing the pieces of the product.

- Water absorption of the sponge cake crumb was determined using the pieces of the finished baked products when dousing them into water at the temperature of $20^{\circ} \mathrm{C}$ for a certain time;

- $\quad$ The porous structure of the sponge cake was determined by means of Zhuravlev probe. For this purpose, in the crumb of the finished semi-finished product, samplings were probed in the form of a cylinder. Then, a sample filled with the crumb was placed on a tray and the crumb was pushed out of it by a plunge. Three samples were made for each semi-finished product. Further, density of the sponge cake product was determined by a calculation method according to a special formula.

- Determination of the nutritional and energy value of the finished products was carried out by calculation in accordance with the Methodological Guidelines for laboratory quality control of public catering products.

The quality of a sponge cake semi-finished product is determined by its ability to absorb water. In this case, intensity and speed of the process ate taken into account. A good quality sponge cake should get wet in water quickly. From the data obtained, with an increase in the doses of the flour mix, the wetness index increases.

The general organoleptic characteristics of the investigated sponge cakes are presented in table 4. 
Table 4. Scoring of organoleptic characteristics of the investigated sponge cakes

\begin{tabular}{|c|c|c|c|}
\hline Indicators & Sample No. 1 & Sample No. 2 & Sample No. 3 \\
\hline Appearance & 5 & 4 & 4.2 \\
\hline Shape & 5 & 4.2 & 4.5 \\
\hline Surface state and colour & 5 & 4.3 & 5.6 \\
\hline Crust thickness & 5 & 5 & 5 \\
\hline Crumb doneness & 5 & 5 & 4 \\
\hline Porous structure & 5 & 3.5 & 4 \\
\hline Elasticity & 4.5 & 4 & 4.5 \\
\hline Taste & 5 & 4.5 & 4.3 \\
\hline Flavour & 4.5 & 4 & 40.3 \\
\hline
\end{tabular}

The organoleptic characteristics of cakes and pastries include appearance, surface, shape, colour, flavour, and taste [8].

In terms of organoleptic characteristics, all the samples had little difference; only with an increase in the share of the flour mix, the colour of the baked products crumb became lighter. The best sample in terms of organoleptic characteristics was sample No. 1 (complete substitution of wheat flour with the mix of oat, corn and gram flour).

This sample had small, thin-walled, uniform pores over the entire surface of the cut, their thickness was uniform up to $1 \mathrm{~mm}$; the crumb of the sample was elastic, easily pressed, after that, it immediately restored its shape. It had a more pronounced flavour; there was some improvement in the condition of the surface of the product.

In terms of organoleptic properties, it could be compared to the control one. The sample is shown in Figure 1.

The studies showed that when wheat flour is substituted with the mix of corn, oat and gram flour, the quality characteristics of samples No. 2 and No. 3 are close to sample No.1.

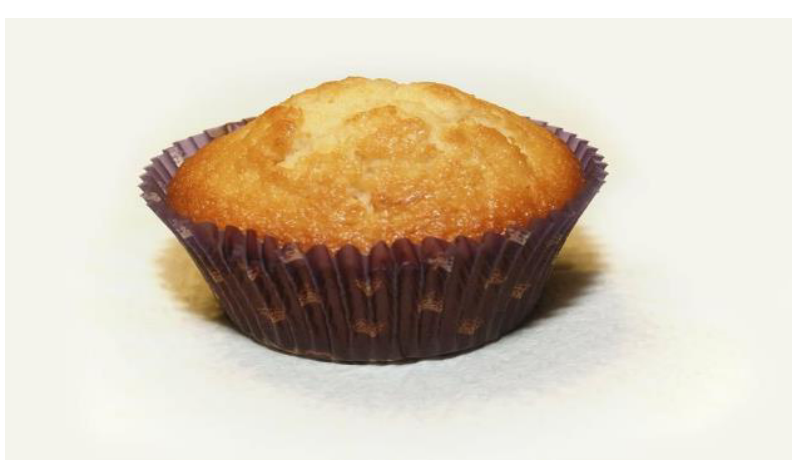

Fig. 1. The final sample (with a complete substitution of wheat flour with corn and oat flour; sugar is substituted with a sweetener; eggs are substituted with gram flour).

The consolidation characteristics of the quality indicators of the investigated sponge cake semi-finished products are presented in Table 5.

Table 5. Quality indicators of the investigated sponge cake semi-finished products

\begin{tabular}{|c|c|c|c|}
\hline Indicators & Sample No. 1 & Sample No. 2 & Sample No. 3 \\
\hline Specific volume, cm per $100 \mathrm{~g}$ & 390.05 & 385.96 & 387.19 \\
\hline Moisture, \% & 25.0 & 23.5 & 24.5 \\
\hline Porous structure, \% & 76.02 & 75.83 & 75.89 \\
\hline $\begin{array}{c}\text { Structural and mechanical properties, } \\
\text { instrument units }\end{array}$ & 6,01 & 5,70 & 5,91 \\
\hline Water absorption, \% & 156.10 & 132.20 & 142.30 \\
\hline
\end{tabular}

Based on the data in Table 5, there is a significant improvement in the sponge cake quality with the complete substitution of wheat flour with a mix of corn, oat and gram flour in comparison with the classic sponge cake formula.

Thus, the following conclusions can be drawn:

1. As can be seen from the data obtained, with the complete substitution of wheat flour with the mix of corn and oat flour, the nutritional value of finished products improves; the share of dietary fiber increases significantly; the calorie content of products decreases.

2. The experiment proved the advisability of substituting high-grade wheat flour in the formulation of a sponge cake semi-finished mix with the mix of oat, corn and gram flour. We recommend using this recipe, since with a complete substitution of wheat flour, an improvement in the quality indicators of sponge cake batter and finished products is observed.

3. The use of oat, corn, and gram flour leads to an extension of the shelf life of sponge cake semi-finished products. The developed formulation can be adapted to the technological process at confectionery enterprises. 


\section{References}

1. A. V. Volkova, V. N. Sysoev, and A. N. Makushin BIO Web of Confю 1700048 (2020)

2. E. A. Pyanikova, A. E. Kovaleva, E. V. Ovchinnikova and L A. Afanasieva IOP Conf. Ser.: Earth Environ. Sci. 677032030 (2021)

3. S. Ya. Koryachkina et. Al. Improv. of tech. of bakery, conf. and pasta for func. purposes 262 (Oryol: FGBOU VPO "State University - UNPK", 2016)

4. A G Belyaev, A. A. Kaluzhskikh, S. G. Boev, A. P. Bashkirev, A. S. Budnikova, and E. S. Kuleshova IOP Conf. Ser.: Earth Environ. Sci. 640042006 (2021)

5. A. E. Kovaleva, E. A. Pyanikova Influence of chokeberry fruit powder on the consumer properties of sponge cakes 812139 (2019)

6. A. E Kovaleva., E. A. Pyanikova Vestnik VSUIT The influence of wild rosehip fruit powder on the consumer properties of sponge cakes 811256 (2019)

7. Ref. and leg. Sys. Cons. Plus [Electronic resource] GOST 5897-90 Confectionery products. Methods for determining organoleptic indicators of quality, size, net weight and components // URL: http://www.consultant.ru

8. E.A. Pyanikova, A.E Kovaleva. Emerg. Iss. in the Glob. Econ.: (IECS) Sales Management Mechanism and Methodologies for Solving the Problems of Special-Purpose Product Management and Sales (Romania, 2017)

9. T. N. Ostroverkhova Confect. and bakery prod. Some aspects of the production of gluten-free products 920 (2012)

10. O. P. Gaidukova, Vegetable raw materials for the production of functional foods 130 (Krasnodar: KubSAU, 2012)

11. Z. A. Kanarskaya, F. K. Khuzin, A. R. Ivleva, V. M. Gematdinova Vestnik VGUIT Trends in the development of confectionery technology 3195 (2016) 